\title{
Pulmonary metastasis: very late relapse of testicular embryonal carcinoma
}

\author{
Martina Flora $^{1}$, Adriano Costigliola ${ }^{1}$, Sabrina Lavoretano ${ }^{1}$, Mariano Mollica ${ }^{1}$, Carmelindo M.E. Tranfa ${ }^{1}$, \\ Fabio Perrotta ${ }^{2}$, Cecilia Calabrese ${ }^{1}$ \\ ${ }^{1}$ Department of Translational Medical Sciences, University of Campania "Luigi Vanvitelli", Naples; ${ }^{2}$ Department of \\ Medicine and Health Sciences V. Tiberio, University of Molise, Campobasso, Italy
}

\begin{abstract}
Testicular carcinoma recurrences represent a rare finding $(1-6 \%$ in non-seminomatous germ cell tumours). However, cases of recurrence have been described many years later. We report a case of late recurrence of embryonic testicular carcinoma, after 26 years, with pulmonary metastases. Following evidence of increase of alpha-fetoprotein (AFP), the patient underwent a total body computed tomography scan that exhibited two pulmonary nodules, one in upper left lobe and other in left hilar region with multiple mediastinal and retrocrural lymph node enlargements All consolidations showed increased sugar uptake value at PET CT. Biopsies of lung consolidations confirmed diagnosis of recurrence of testicular carcinoma.
\end{abstract}

\section{Introduction}

Late relapses (LR) of a testicular cancer, defined as tumour recurrence more than 2 years after complete remission following primary treatment, are rare occurrences with $2.6 \%$ of incidence rate

Correspondence: Adriano Costigliola, Department of Translational Medical Sciences, University of Campania "Luigi Vanvitelli",

Via Leonardo Bianchi c/o Ospedale Monaldi, 80131 Naples, Italy. Tel. +39.22223185.

E-mail: adriano.costigliola@studenti.unicampania.it

Contributions: All the authors made a substantive intellectual contribution, performed part of the experiments. MF, AC, contributed equally. All the authors have read and approved the final version of the manuscript and agreed to be accountable for all aspects of the work.

Conflict of interest: The authors declare that they have no competing interests, and all authors confirm accuracy.

Key words: Embryonal carcinoma; pulmonary metastasis; lung cancer; testicular cancer.

Received for publication: 30 November 2019.

Accepted for publication: 28 January 2020.

${ }^{\circ}$ Copyright: the Author(s), 2020

Licensee PAGEPress, Italy

Monaldi Archives for Chest Disease 2020; 90:1206

doi: 10.4081/monaldi.2020.1206

This article is distributed under the terms of the Creative Commons Attribution Noncommercial License (by-nc 4.0) which permits any noncommercial use, distribution, and reproduction in any medium, provided the original author(s) and source are credited.
[1]. However, very late recurrences of testicular cancers that occur even more than 5 years after the treatment are reported. The most frequent location of LR of testicular cancers is the retroperitoneal space, while the lungs and the mediastinal lymphnodes are less frequently involved [1]. When it is located in lung, differential diagnosis with primary lung cancer is required; in these cases, histological assessment and bio-molecular profiling assist diagnosis [2-7]. Chemo-resistance is common in late relapses especially of nonseminomatous germ cell tumours, resulting in poor prognosis [8].

\section{Case Report}

We report a case of a 50-years old man, smoker of 18 packyears with medical history of testicular neoplasia, an embryonic carcinoma, twenty-six years ago, treated with right orchifunicolectomy followed by 4 cycles of adjuvant chemotherapy with Platinum/ Etoposide/Bleomycin (PEB). No alterations were ever detected during the annual follow-ups of both imaging and blood serology.

After 26 years from the primary treatment, during an annual follow-up, an increase of alpha-fetoprotein (AFP), $400 \mathrm{UI} / \mathrm{ml}$ (n.v. 0.1 5.5), was found. Total body computed tomography scan and positron emission tomography scan PET/TC revealed two pulmonary nodules, one in upper left lobe (10 $\mathrm{mm}$ SUV max 2.8) the other in left hilar region (23 mm SUV max 4.6) (Figure 1). Furthermore, multiple mediastinal and retrocrural lymph node enlargements were detected (SUV max 9.3) (Figure 2). He presented in good general condition of health. He reported only mild exertional dyspnoea, no asthenia or weight loss. Laboratory tests, spirometry and blood gas analysis were otherwise normal, except for a slight reduction in alveolar-capillary diffusion capacity and a slight increase of specific neuron enolase (17.4 $\mathrm{ng} / \mathrm{mL})$. Bronchoscopy and TBNA of station $4 \mathrm{~L}$ were performed. The pathological assessment revealed carcinoma neoplastic cells resulting AFP + TTF- at immunohistochemical staining compatible with embryonic carcinoma metastases (Figure 3). The final diagnosis was pulmonary relapse of embryonic carcinoma. The patient was referred to oncology department and started chemotherapy protocol, started a second line chemotherapy protocol a with Cisplatin (P), Etoposide (E), Ifosamide (I) (PEI). Chemotherapy treatment is still ongoing, normalization of tumour markers has been detected and the first imaging control after therapy is scheduled

\section{Discussion}

Despite good response to initial treatment, about $10-30 \%$ of patients with testicular cancer develop recurrence, usually within 
the first 2 years after complete response to treatment. In a pooled analysis of 5880 patients with testicular cancer Oldenburg et al. found late relapses in $3.2 \%$ of non-seminoma and $1,4 \%$ of semino- ma patients [1]. Generally, LRs happen in the first 5 years after treatment. In a population-based analysis, Oldenburg et al. report recurrence beyond 5 years, called very late relapses (VLR) in $0.5 \%$
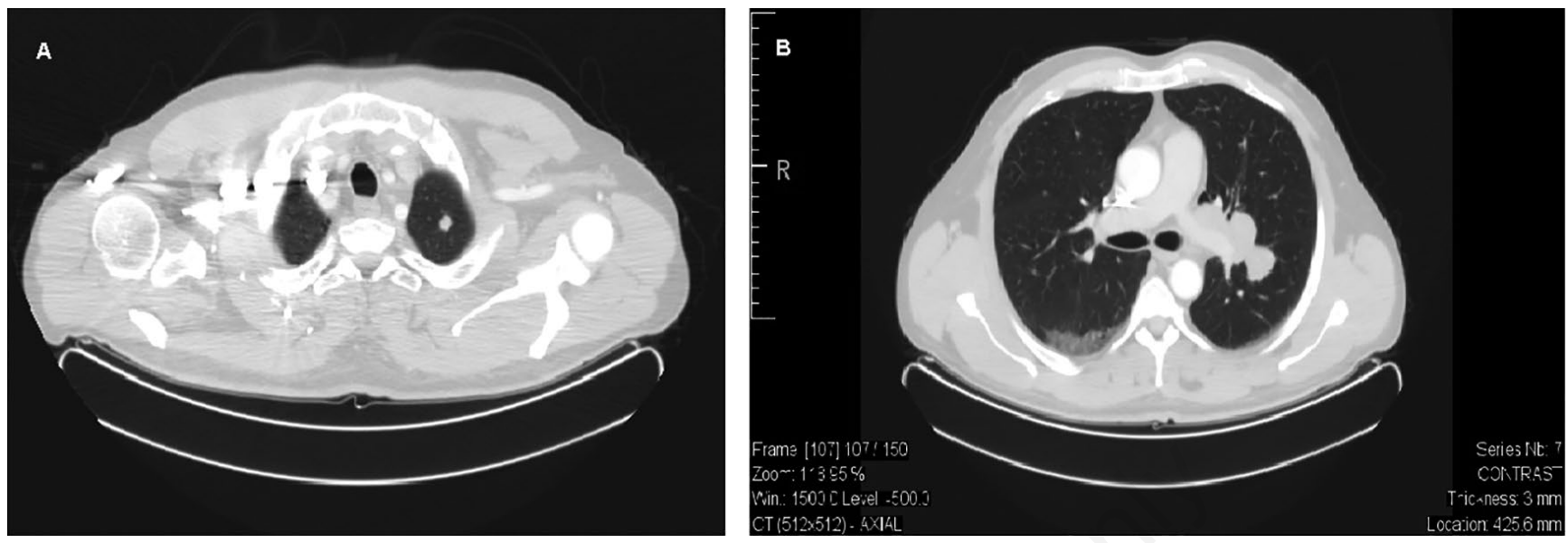

Figure 1. Thoracic CT scan. A) Nodule in upper left lobe $(10 \mathrm{~mm})$. B) Nodule in left hilar region $(23 \mathrm{~mm})$.
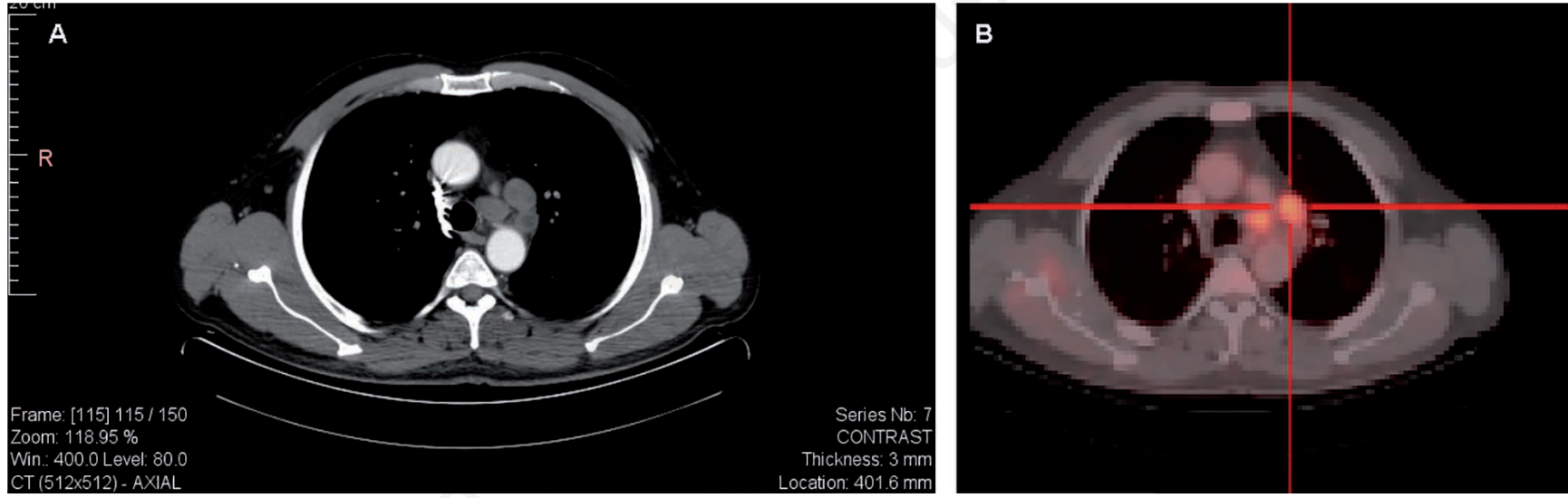

Figure 2. Multiple mediastinal lymphnode enlargement. A) Multiple pre-vascular lymphadenopathies, in the APW and posterior mediastinum medially to the descending aorta $(\max$ diameter $25 \mathrm{~mm}$ ). B) Lymphadenopathies aortopulmonary window (diameter $25 \mathrm{~mm}$ SUV max 6.4).

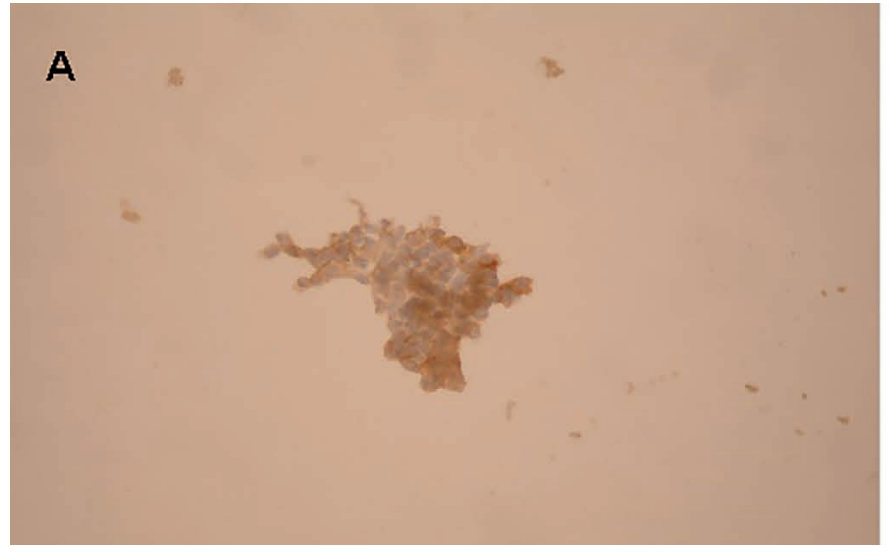

Figure 3. Neoplastic cells AFP+ (A) and TTF1- (B). 
of patients [8]. Geldart et al. describe 9 years of median time to relapse, while other authors reported 5.4-7.1 years of median time to relapse [9]. Our patient presented a recurrence of embryonic carcinoma after 26 years. VLR after 20 years from initial presentation are extremely rare. Few cases are reported in literature in testicular cancer: Kalaitzis et al. (choriocarcinoma and embryonal carcinoma 23 years), Pavic et al. (teratoma 32 years), Mukhtar et al. (42 years) and Akar et al. (non-seminomatous 24 years), Arafat (teratoma 27 years) [10-14]. The most frequent location of late relapse of both seminomatous and non-seminomatous germ cell tumours are retroperitoneal space followed by lung and mediastinum (25\%) [1].

Among the different subtypes, teratoma is the most frequent subtype in the LRs of germ cell tumours, followed by yolk sac tumour alone or with teratoma. The others subtypes, including embryonic carcinoma, represent $20 \%$ of patient with late recurrence. Choriocarcinoma and seminoma are rarely seen [1]. Early relapses have good response to salvage regimens in a significant proportion of patients [15]. Conversely, LRs of non seminomatous germ cell cancer have poor response to chemotherapy. Complete surgical resection in localized disease is related to the best outcome and represent the most important part of treatment approach [8]. Successful management of LRs is dependent on early recognition. The recurrence onset is, in the majority of case, symptomatic. However, up to $50 \%$ of patients have elevated tumour markers at presentation of relapse [15]. At the moment an international consensus about the optimal management for LRs of testicular cancer is still lacking and follow-up after 5 years is generally not recommended in testicular cancer [16]. George et al. proposed an annually follow up for life with history and physical, tumour markers, and chest X-Ray [17]. All testicular cancers are potentially at risk for early and late relapse. Our case underlines the importance of extended follow up of more than five years to prompt detection of late relapses. However, considering of the potential difficulties to perform lifelong follow-up, we suggest, in a patient with a history of embryonic carcinoma, to not underestimate the possibility of late metastasis.

\section{References}

1. Oldenburg J, Martin JM, Fosså SD. Late relapses of germ cell malignancies: incidence, management, and prognosis. J Clin Oncol 2006;24 5503-11.

2. Zhang YQ, Bianco A, Malkinson AM, et al. BARD1: an independent predictor of survival in non-small cell lung cancer. Int J Cancer 2012;131:83-94.
3. Illiano M, Nigro E, Sapio L, et al. Adiponectin down-regulates CREB and inhibits proliferation of A549 lung cancer cells. Pulm Pharmacol Ther 2017;45:114-20.

4. Di Zazzo E, Polito R, Bartollino S, et al. Adiponectin as link factor between adipose tissue and cancer. Int $\mathrm{J}$ Mol Sci 2019;20. pii: E839.

5. Nigro E, Stiuso P, Matera MG, et al. The anti-proliferative effects of adiponectin on human lung adenocarcinoma A549 cells and oxidative stress involvement. Pulm Pharmacol Ther 2019;55:25-30.

6. Bianco A, Perrotta F, Barra G, et al. Prognostic factors and biomarkers of responses to immune checkpoint inhibitors in lung cancer. Int J Mol Sci 2019 5;20:4931.

7. Nigro E, Imperlini E, Scudiero O, et al. Differentially expressed and activated proteins associated with non small cell lung cancer tissues. Respir Res 2015;16:74.

8. Oldenburg J, Alfsen GC, Waehre H, Fosså SD. Late recurrences of germ cell malignancies: a population-based experience over three decades. Br J Cancer 2006;94:820-7.

9. Geldart TR, Gale J, McKendrick J, et al. Late relapse of metastatic testicular nonseminomatous germ cell cancer: Surgery is needed for cure. BJU Int 2006;98:353-8.

10. Kalaitzis C, Bantis A, Tsakaldimis G, et al. Osteolytic bone destruction resulting from relapse of a testicular tumour 23 years after inguinal orchiectomy and adjuvant chemotherapy: A case report. J Med Case Rep 2009;3:8702.

11. Pavic M, Meeus P, Treilleux I, Droz JP. Malignant teratoma 32 years after treatment of germ cell tumor confined to testis. Urology 2006;67:846.e11-3.

12. Mukhtar S, Beatty J, Agrawal S, et al. Germ cell tumour: Late recurrence after 43 years. Ann R Coll Surg Engl 2011;93:e24-6.

13. Akar E, Tural D, Arslan D, et al. Late relapse of testicular cancer: Recurrence after 24 years and treatment with chemotherapy alone. J Can Res Ther 2015;11:661.

14. Arafat W, Albany C, Ulbright TM, et al. Very late relapse of germ cell tumor as a teratoma: a case report and review of the literature. J Surg Case Rep 2014; 2014:rju051.

15. Einhorn LH, Williams SD, Chamness A, et al. High-dose chemotherapy and stem-cell rescue for metastatic germ-cell tumors. N Engl J Med 2007;357:340-8.

16. Honecker F, Aparicio J, Berney D, et al. ESMO Consensus Conference on testicular germ cell cancer: diagnosis, treatment and follow-up. Ann Oncol 2018;29:1658-86.

17. George DW, Foster RS, Hromas RA, et al. Update on late relapse of germ cell tumor: A clinical and molecular analysis. J Clin Oncol 2003;21:113-22. 